\title{
Soberania e Biopolítica: dos nexos entre poder soberano e biopoder no pensamento político de Michel Foucault e de seus usos na atualidade
}

Sovereignty and Biopolitics: the links between sovereign power and biopower in Michel Foucault's political thought and its current uses

\section{André Constantino Yazbek}

Universidade Federal Fluminense, Rio de Janeiro, RJ, Brasil

\section{Resumo}

O presente trabalho examina as relações entre as noções de poder soberano, biopoder e governamentalidade liberal no pensamento de Michel Foucault a fim de explorar alguns de seus nexos e de seus possíveis usos em nossa atualidade. Nesse sentido, ao passo que a primeira e a segunda parte deste artigo procuram mapear a temática da soberania e do biopoder no pensamento do próprio Foucault, a última parte dedica-se a assinalar, pontualmente, as interlocuções que Giorgio Agamben, Roberto Esposito e Achille Mbembe estabelecem com o tema em foco.

Palavras-chave: Michel Foucault. Soberania. Biopoder. Governamentalidade Liberal. 


\section{Abstract}

This paper examines the relationship between the notions of sovereignty power, biopower and liberal governmentality in Michel Foucault's thought in order to explore some of its links and possible uses in our actuality. In this sense, while the first and second part of this article tries to map the theme of sovereignty and biopower in Foucault's own thinking, the last part is dedicated to pointing out, punctually, the interlocutions that Giorgio Agamben, Roberto Esposito and Achille Mbembe establish with the theme in focus.

Keywords: Michel Foucault. Sovereignty. Biopower. Liberal Governmentality.

I.

É nos quadros de suas investigações sobre a sexualidade como lugar de formação dos dispositivos de saber-poder, e nos marcos de suas lições ministradas no Collège de France ao longo da segunda metade da década de 1970, que Michel Foucault será levado a se interessar sistematicamente pelo tema da promoção da vida a objeto central dos exercícios do poder político. Através de uma análise da evolução do sentido do sacrifício político, quer dizer, da possibilidade, para o Estado, de exigir a morte de um cidadão — seja por razões exteriores ou interiores, seja enviando-o à guerra ou exigindo-lhe o sacrifício do suplício -, Foucault ressalta o fato de que, no curso de nossa modernidade, o velho direito de vida e de morte do soberano sobre seus súditos se convertera em uma exigência de "fazer viver", de gerir a vida de seus cidadãos. Eis o ponto de mutação, tal como Foucault o delimita, entre a forma de exercício de poder da soberania clássica (manifesta no direito de causar a morte ou deixar viver) e uma outra, a do biopoder, cuja tarefa será a de investir exaustiva e extensivamente sobre a vida:

A partir da idade clássica, o ocidente conheceu uma mudança bastante profunda nesses mecanismos de poder [da soberania clássica]. O "confisco" [da vida] tende a não ser mais sua forma principal, mas apenas uma peça, entre outras, com função de excitação, de reforço, de controle, de vigilância, de majoração e de organização das forças que a ela se submetem: um poder destinado a produzir forças, a fazê-las crescer e as ordenar mais do que barrá-las, dobrá-las ou destruí-las. Desde então, 
o direito de morte tenderá a se deslocar, ou ao menos se apoiar sobre as exigências de um poder que gere a vida, ordenando-se em função de suas demandas (FOUCAULT, 1976, p. 179).

Assim, para justificar a estes o sacrifício político, o Estado passa a evocar cada vez menos o direito soberano de dispor da existência de seus cidadãos e cada vez mais a exigência de favorecer o interesse vital dos indivíduos naquilo que concerne a uma majoração de suas forças coletivas. Portanto, a possibilidade, para o Estado, de privar um cidadão de sua vida passa de uma forma negativa para uma forma positiva: o sacrifício de indivíduos torna-se um meio negativo de atingir um bem positivo - a manutenção ou majoração da vida do conjunto dos cidadãos; e o que está no centro desta mutação, desta reorganização dos dispositivos de poder, é a integração da dimensão biológica no campo de aplicação da política, ou seja: uma biopolítica, nos termos de Foucault (FOUCAULT, 2000, p. 289). Isso significa que o conjunto dos seres vivos, e sobretudo o homem - enquanto corpo e espécie cuja existência se desenvolve em interação constante com seu meio - , tendem a tornar-se o objeto principal e dominante da prática política moderna, mormente a estatal. E é também na qualidade de ser vivo que o homem se tornará, igualmente, objeto de interesse de uma prática científica que produz, a partir dele e sobre ele, um precioso saber que provoca ou facilita o desenvolvimento das técnicas políticas gestionárias características da modernidade (saberes tais como a própria medicina, mas também a climatologia, a geografia, a estatística, o urbanismo e a arquitetura - com suas cidades-modelo - a demografia, a eugenia, etc.). Em outros termos: o abundante conhecimento sobre o homem (a um só tempo como espécie viva e indivíduo), assim como sua relação com o meio, servem ao mesmo tempo de condição de possibilidade e de finalidade para a intervenção política de uma arte de governo que possui no controle da vida sua superfície de incidência. Esta integração do homem-espécie na esfera da política - inédita (segundo a hipótese de Foucault) - constitui, a partir do século XVIII, o sintoma de uma mutação central no regime geral das estratégias e dispositivos de poder que caracterizam o Ocidente: 
O homem ocidental aprende pouco a pouco o que é ser uma espécie viva em um mundo vivo, ter um corpo, condições de existência, probabilidades de vida, uma saúde individual e coletiva, forças que se pode modificar [majorar ou diminuir] e um espaço no qual se pode reparti-las de modo otimizado. Pela primeira vez na história, sem dúvida, o biológico se reflete no político; o fato de viver não é mais este sustentáculo inacessível que só emerge de tempos em tempos, no acaso da morte e em sua fatalidade; em parte, ele passa para o campo de controle do saber e da intervenção do poder. Este não estará mais somente às voltas com sujeitos de direito sobre os quais seu último acesso é a morte, porém com seres vivos, e o império que poderá exercer sobre eles deverá situar-se no nível da própria vida; é o fato de poder encarregar-se da vida, mais do que a ameaça da morte, que lhe dá acesso ao corpo. /... / deveríamos falar de "bio-política" para designar o que faz com que a vida e seus mecanismos entrem no domínio dos cálculos explícitos e façam do poder-saber um agente de transformação da vida humana (Idem, p. 187-188).

Nestes termos, a noção de biopolítica visa a identificar toda a política que tenha na vida a superfície de inscrição de suas formas de exercício de poder, ou seja, que tenha no próprio fato biológico seu objeto específico: a biopolítica se endereça não ao corpo individual, mas à "multiplicidade dos homens" na "medida em que ela forma [...] uma massa global afetada por processos de conjunto que são próprios da vida" (FOUCAULT, 2000, p. 289); de outra parte, o biopoder pode ser caracterizado pela gestão da zoé em geral e de todo aquilo que se relaciona com a existência biológica do indivíduo compreendido como espécime pertencente a um conjunto de seres viventes: trata-se, portanto, do "conjunto de mecanismos pelos quais aquilo que, na espécie humana, constitui suas características biológicas fundamentais vai poder entrar em uma política, em uma estratégia política, em uma estratégia geral de poder" (FOUCAULT, 2004a, p. 3). Mas dada a força e as implicações da tese foucaultiana - Foucault certamente não é o inventor da noção de "biopolítica", mas o modo como ele repôs em circulação o termo e o requalificou conceitualmente teve por efeito, nas palavras de Roberto Esposito, uma modificação de "todo o quadrante da filosofia 
política" (2010, p. 29) —, o manejo da temática deste poder gestionário da vida permite circunscrever criticamente o perímetro de algumas noções clássicas da filosofia política a fim de pôr à prova sua capacidade interpretativa diante de complexos processos econômicos, sociais e políticos de nossa contemporaneidade ${ }^{1}$. Em que, precisamente, o vigor das interlocuções e apropriações que a temática da biopolítica e do biopoder tem suscitado entre autores tais como o próprio Roberto Esposito, Giogio Agamben e Achille Mbembe, entre outros.

Nas linhas que se seguem, nossas pretensões são pontuais e circunscritas, e constituem mais uma peça em um debate concernente às relações entre biopoder e poder soberano na genealogia foucaultiana: trata-se de recuperar a temática do biopoder em Foucault relacionando-a ao aspecto relativo à lógica liberal que caracteriza a instauração dos modernos estados biopolíticos e ao papel que a soberania, como direito que marca seu domínio sobre vida infligindo a morte, é chamada necessariamente a desempenhar no interior desta forma de poder estatal gestionário da vida. Para tanto, e evidentemente sem a pretensão de esgotar a temática, levaremos a termo, na última parte deste artigo, algumas articulações com elementos pontuais e exemplares das obras de Agamben, Esposito e Mbembe naquilo que toca ao debate contemporâneo acerca do nexo entre o biopoder e a violência soberana estatal.

\section{II.}

Comecemos por sublinhar, como o próprio Foucault o fará em diferentes contextos, a importância da imbricação entre o biopoder com sua lógica de intervenção biopolítica para a regulação de fenômenos populacionais — , a emergência e o desenvolvimento do capitalismo e, como seu correlato, da racionalidade política dita liberal. Assim, não se deve perder de vista o fato de que já a primeira ocorrência da noção de biopolítica na obra foucaultiana, cujo registro se encontra em

\footnotetext{
1 Para ficarmos no exemplo mais simples, mais evidente, façamos nossas as palavras de Francesco Paolo Adorno: "Basta pensar no desenvolvimento das biotecnologias médicas: se permanecemos no interior de uma concepção clássica da filosofia política, elas não serão senão, no fundo, um fenômeno residual, no cruzamento entre a ciência e a moral. Por outro lado, se adotamos a perspectiva da biopolítica, sua função torna-se transparente: elas representam uma das modalidades de controle do político sobre a vida com vistas a sua otimização produtiva" (ADORN0, 2008, p. 3).
} 
uma conferência dada por Foucault em 1974 na Universidade Estadual do Rio de Janeiro (UERJ), intitulada "O nascimento da medicina social", diz respeito à hipótese segundo a qual, com o advento e a consolidação do capitalismo, o que ocorrera não fora a passagem de uma medicina coletiva para uma medicina privada, mas justamente o contrário, - o que significa que o capitalismo emergente, entre fins do século XVIII e início do XIX, "socializou um primeiro objeto que foi o corpo enquanto força de produção, força de trabalho": "Foi no biológico, no somático, no corporal que, antes de tudo, investiu a sociedade capitalista", e é nesse sentido que se pode dizer que o corpo, na modernidade, é uma "realidade bio-política" (FOUCAULT, 2002, p. 80). Ademais, quanto ao tema do liberalismo propriamente dito, objeto do curso de 1979, intitulado Nascimento da biopolítica, ele constitui a forma da experiência histórica e da racionalidade política no interior das quais organizou-se o poder sobre a vida no Ocidente: "Só depois que soubermos o que era esse regime governamental chamado liberalismo e que poderemos, parece-me, apreender o que é a biopolitica" (FOUCAULT, 2004b, p. 24). ${ }^{2}$

De fato, o tipo de cálculo, de conhecimento, de controle, de organização e de gestão de massas necessário a emergência e consolidação de uma economia capitalista são todos, em algum grau, instrumentos

2 É importante sublinhar, aqui, que ao longo das lições de Nascimento da biopolítica, dedicadas primordialmente à análise e à descrição positiva da racionalidade de governo propriamente liberal, Foucault acompanhará os deslocamentos desta "nova razão governamental" em direção a emergências dos fenômenos políticos característicos do neoliberalismo alemão ( 0 Ordoliberalismo) e estadunidense (o neoliberalismo da chamada Escola de Chicago). Assim, paulatinamente, Foucault mapeará um conjunto de diferenças entre liberalismo e neoliberalismo que poderiam ser resumidas no seguinte aspecto: se em ambos os casos o mercado é a chave de inteligibilidade e de organização prática das formas de vida social, resta que, para o primeiro, o liberalismo clássico, o princípio do mercado é a troca como sinal de equivalência, ao passo que, para 0 segundo, o neoliberalismo contemporâneo ao século XX, o princípio do mercado é a concorrência (FOUCAULT, 2004b, p. 121-122). Nos termos das análises foucaultianas, isso significa, fundamentalmente, que a passagem do liberalismo para o neoliberalismo corresponde à passagem do mercado definido e descrito a partir da troca livre entre parceiros que estabelecem uma equivalência de valores - 0 que pressupõe uma "situação entre iguais" - para um outra compreensão prática, na qual o mercado, tendo na concorrência o seu elemento definidor, deve ser absolutamente desregulamentado para assegurar desigualdades sem, no entanto, exacerbá-la a ponto de aniquilar os agentes econômicos (Idem, p. 148). Em consequência, Foucault sublinhará, sobretudo no neoliberalismo estadunidense, a "generalização da forma econômica do mercado" a ponto dela se constituir em "princípio de inteligibilidade, princípio de decifração das relações sociais e dos comportamentos individuais" (Idem, p. 248-249). Para os propósitos deliberados deste artigo - que se propõe a apreender a lógica da racionalidade liberal em sua ossatura mais geral -, não faremos referências às distinções entre liberalismo e neoliberalismo a não ser pontualmente e em poucas ocasiões. 
desenvolvidos nos quadros de um poder que reúne as condições materiais de existência dos homens e de seu meio natural circundante, para incidir sobre os corpos produtivamente - não para o suplício ou a morte, mas para a maximização de suas energias -, quer dizer, um poder que gere a vida em seus desenvolvimentos maciços e, nesse sentido, propõe-se a conduzir condutas; e é nisso que reside, em última instância, o significado do neologismo foucaultiano de governamento. ${ }^{3}$ Com efeito, no contexto dos desenvolvimentos crescentes de uma economia capitalista, para que as relações de produção sejam majoradas, é indispensável que um controle eficaz sobre os indivíduos (tanto em seu aspecto de corpo singular quanto em sua dimensão de espécie vivente) possa ser exercido de maneira a otimizá-los em sua força produtiva e em sua vida mesma, - e isso tanto em seus comportamentos individuais (disciplina) quanto em suas relações coletivas (gestão populacional) (FOUCAULT, 1976, p. 185). Sendo assim, o biopoder não substitui nem exclui o poder disciplinar, - apenas o distribui diferentemente e, nesses termos, responde à emergência da população como "novo objeto" das práticas e dos cálculos do poder político, de sorte que a "população" constitui "uma ideia e uma realidade sem dúvida absolutamente modernas com relação ao funcionamento político / ... / e às teorias políticas anteriores ao século XVIII" (FOUCAULT, 2004a, p. 13). Em outros termos: para Foucault, a grande novidade nos rearranjos das técnicas e dispositivos de poder no século XVIII teria sido a emergência da população como "problema econômico e político": a população-riqueza, a população-mão-de-obra ou capacidade-de-trabalho, a população em equilíbrio tênue entre seu crescimento próprio e os recursos disponíveis (BLANCHETTE, 2006, p. 5). Assim, os governos estatais passam

3 Por governamento ou governamentalidade ("gouvernementalite") deve-se compreender, em Foucault, uma forma de apreensão das relações de poder como governo das condutas em sentido amplo, quer dizer, como um "conjunto de ações sobre ações possíveis": " 0 poder, no fundo, é menos da ordem do afrontamento entre dois adversários, ou do vínculo de um com relação ao outro, do que da ordem do 'governo'. Devemos deixar para este termo a significação bastante ampla que tinha no século XVI. Ele não se referia apenas às estruturas políticas e à gestão dos Estados; mas designava a maneira de dirigir a conduta dos indivíduos ou dos grupos: governo das crianças, das almas, das comunidades, das famílias, dos doentes. Ele não recobria apenas formas instituídas e legítimas de sujeição política ou econômica; mas modos de ação mais ou menos refletidos e calculados, porém todos destinados a agir sobre as possibilidades de ação dos outros indivíduos. Governar, neste sentido, é estruturar o eventual campo de ação dos outros" (FOUCAULT, 2001, p. 1056, grifo nosso). 
a operar, modernamente, em um cálculo político no qual suas relações não são simplesmente relações de governo para com sujeitos de direito ou para com um "povo", mas sim para com populações e a gestão dos fenômenos variáveis que lhe são próprios - taxas de natalidade, de fecundidade, de mortalidade, de epidemias, de atividade econômica, distribuição espacial, etc (FOUCAULT, 2000, p. 298-290).

Esquematicamente, portanto, se poderia apresentar a relação entre biopoder e liberalismo (na condição de racionalidade biopolítica) do modo como se segue: a população, naquilo que caracteriza a produção e reprodução das formas materiais da existência propriamente biológica, com as variáveis e regularidades aí implicadas, formará o "nível de pertinência para a ação de um governo" (FOUCAULT, 2004a, p. 68) biopolítico; tal nível de pertinência, por sua vez, demanda uma lógica liberal de governamento, posto que a gestão da população exige um tipo de intervenção governamental cuja ação é reguladora, mas não constitutiva, isto é: intervir, para a racionalidade política liberal, é precisamente identificar e deixar agir a (suposta) naturalidade normativa dos fenômenos populacionais, a ser conhecida pela economia política, que é um saber relativo ao curso natural da circulação das "coisas" e dos "homens" (FOUCAULT, 2004b, p. 18-19). Daí que os dispositivos de poder característicos do biopoder e da racionalidade liberal, compreendida em termos de uma biopolítica, sejam o que Foucault nomeia de "dispositivos de segurança" ou "seguridade": trata-se de um conjunto de dispositivos de seguridade pública (que se efetivam mormente pela instituição da saúde pública, do saneamento e das reformas das cidades) para o controle de uma massa de indivíduos (apreendidos na condição de seres viventes) em espaço aberto, um controle que, paradoxalmente, deve favorecer a circulação das coisas e dos indivíduos - segundo a racionalidade propriamente liberal da produção e da circulação de mercadorias - e que implicará, com efeito, uma outra geometria espacial do poder (Idem, p. 22-23).

Portanto, a questão política moderna, historicamente, diz respeito ao fato de que o fenômeno europeu de expansão demográfica no século XVIII tornara praticamente inoperante os instrumentos clássicos de exercício do poder correspondentes à soberania clássica e à razão de 
Estado, cujo modelo de administração é o de um "Estado de Polícia" ou Polizeistaat (no sentido de uma regulamentação indefinida e exaustiva da atividade econômica e da vida dos súditos, a fim de articulá-las em um continuum administrativo-legal (FOUCAULT, 2004a, p. 174)). Sendo assim, em lugar de enformar a vontade política dos cidadãos exclusivamente por meio das leis, dos regulamentos e do aparato repressivo que lhes acompanham - tal como pretende a soberania política - , tratava-se agora, para a lógica biopolítica (e liberal) de gestão populacional, de regular um conjunto constituído por processos que possuem sua regra interna de funcionamento, sua lógica própria, - processos biológicos e econômicos de trocas e distribuição das riquezas, de nascimentos e mortes, de doenças, epidemias, diminuição ou aumento demográfico, fenômenos cuja erradicação, como tal, é impossível, mas cuja regulação parece factível. Assim, nas palavras do próprio Foucault,

A população é um conjunto de elementos, no interior do qual podem-se notar constantes e regularidades até nos acidentes, no interior do qual pode-se identificar o universal do desejo produzindo regularmente o benefício de todos e a propósito do qual pode-se identificar certo número de variáveis de que ele depende e que são capazes de modificá-lo. Com a tomada em consideração / ... / dos efeitos próprios à população, creio que temos um fenômeno muito importante: é o ingresso, no campo das técnicas de poder, de uma natureza que não é aquilo a quê, aquilo acima de quê, aquilo contra o quê o soberano deve impor leis justas. [...] Tem-se uma população cuja natureza é tal que é no interior dessa natureza, com a ajuda dessa natureza, a propósito dessa natureza que o soberano deve desenvolver procedimentos refletidos de governo. Em outras palavras, no caso da população, tem-se algo bem diferente de uma coleção de sujeitos de direito diferenciados por seu estatuto, sua localização, seus bens, seus cargos, seus ofícios; tem-se um conjunto de elementos que, de um lado, se inserem no regime geral dos seres vivos e, de outro, apresentam uma superfície de contato para transformações autoritárias, mas refletidas e calculadas (Idem, p. 76-77, grifo nosso).

Evidentemente, o ingresso da população como sujeito e objeto dos cálculos do poder político, para fins de majoração positiva de suas forças produtivas, de seu incremento, não implica o desparecimento do aparato legal repressivo e de suas operações materiais - como se pode 
observar na referência de Foucault às transformações autoritárias —, mas acarreta sua redistribuição segundo uma lógica diversa, cujo ponto de aplicação não é mais o sujeito de direitos, mas o sujeito de interesse ou o homo economicus, sobretudo tendo-se em vista a emergência do neoliberalismo (FOUCAULT, 2004b, p. 231). Nestes termos, a lógica indefinida de acumulação do capital converte-se em modalidade subjetiva o homo economicus representa um regime de gestão social e produção de formas de vida que desaguará no neoliberalismo contemporâneo - , a ponto de destituir a soberania política do campo da economia tal como compreendida modernamente, isto é, como economia política: segundo uma lógica utilitarista e empirista, o próprio "interesse aparece com um princípio empírico do contrato [social]" (FOUCAULT, 2004b, p. 373), com a consequente submissão do político ao econômico ${ }^{4}$. A esse respeito, a interpretação da "mão invisível" smithiana por Foucault é exemplar: como correlato deste "aparecimento" do homo economicus, a célebre metáfora da "mão invisível" de Adam Smith leva a termo uma desqualificação da possibilidade de um soberano econômico, isto é, afirma a "impossibilidade que o soberano possa ter, sobre o mecanismo econômico, um ponto de vista que totalize cada um dos elementos e permita combiná-los artificial ou voluntariamente" (Idem, p. 284). Assim, fundada sobre a incognoscibilidade da totalidade do processo econômico, o homo economicus aparecerá, para a racionalidade liberal, como a "única ilha de racionalidade possível no interior de um processo econômico cujo caráter incontrolável [...] funda [...] a racionalidade do comportamento atomístico" dos indivíduos (Idem, p. 285).

Deste modo, comparando as proximidades e distâncias entre a obra de Karl Marx e aquela de Foucault, Jacques Bidet parece tocar o ponto nodal da crítica foucaultiana do capitalismo ao pontuar que o marxismo centra sua reflexão sobre a noção mesma de "capital" e, portanto, anuncia a "pesquisa do lucro" (ou da mais-valia) como sua

4 Caberá a Agamben, como sabemos, uma profícua exploração, em chave de análise genealógica e biopolítica, das relações entre o político e o econômico no âmbito das democracias modernas, explorando os domínios do direito e da teologia, domínios não explorados por Foucault. Assim, dirá 0 autor de 0 reino e a glória, "a vocação econômico-governamental das democracias contemporâneas não é um incidente de percurso, mas parte integrante da hereditariedade teológica da qual são depositárias" (AGAMBEN, 2007a, p. 160). 
pedra de toque, ao passo que, em Foucault, a noção central é a de "liberalismo" e, nesse sentido, como vimos, a tarefa privilegiada será a de descrever e analisar a realidade de um poder encarregado de "uma política da vida, uma 'biopolítica'” (BIDET, 2014, p. 155). São, portanto, ambições teóricas diferentes, que respondem a horizontes históricos diversos: se Marx tem em vista a análise de uma "estrutura da sociedade" - o capitalismo é um "modo de produção" que implica uma "superestrutura que lhe faz corpo" - , Foucault, por seu turno, tem por objeto próprio o "liberalismo" compreendido como prática de governamento no sentido amplo do neologismo foucaultiano, quer dizer: um conjunto de tecnologias de governo dos indivíduos para a condução de suas condutas (Idem, p. 156). Dito de outro modo, o liberalismo (e também o neoliberalismo), tal como Foucault o aborda, não é uma teoria política ou filosófica, mas antes uma prática de governo, - de sorte que a genealogia foucaultiana se encontra em condições de apreender o liberalismo fora dos enquadramentos legais e morais do liberalismo filosófico, reduzindo-o, de certa forma, unicamente a sua função de prática gestionária das populações e ao saber econômico que lhe corresponde. Daí o fato de que, para Foucault, não se tratava de elaborar uma teoria do Estado, mas sim uma teoria do governamento, ou das formas da racionalidade governamental, sendo o Estado, ele próprio, o correlato de tais formas de governar. Neste termos, liberalismo e neoliberalismo são formas de governamento que engendram, como seu correlato histórico, uma forma de Estado que lhes será correspondente. E é nesse sentido que se deve compreender a questão que Foucault propõe aos seus ouvintes na aula do dia 08 de março de 1978 do curso Segurança, território, população: "E se o Estado não fosse senão uma maneira de governar? Se o Estado não fosse senão um tipo de governamentalidade?" (FOUCAULT, 2004a, p. 253).

Assim, tratava-se, na reflexão foucaultiana, de apreender o momento genealógico no qual se deu o desbloqueio de uma arte de governo que se reinscreveria no espaço do pensamento e da ação política dos séculos XVII e XVIII a partir do problema da população; fora necessário que o governo do oikos extrapolasse o modelo da família para que, por meio da formação de uma prática e de um saber de Estado - a 
estatística - , a economia pudesse "recentrar-se em um certo nível de realidade que caracterizamos agora como econômica" (FOUCAULT, 2004a, p. 107) e que exige, por seu turno, uma prática de governamento que lhe seja própria (dada a incorporação, pelo poder político moderno, e em escala ampliada, da regulação de processos destinados anteriormente ao oikos); um governamento que, a princípio, representa um corte com relação às formas de exercício de poder típicas da soberania clássica, - cujo objeto próprio era antes o domínio territorial e jurídico-institucional da legalidade e da unidade do corpo soberano do que a gestão populacional (FOUCAULT, 2004ba, p. 68).

III.

Mas há aqui, a propósito das noções de governamento, biopoder e da compreensão do liberalismo em chave de governamentalidade biopolítica, um aspecto bastante relevante concernente ao papel que a soberania viria a representar nos modernos estados biopolíticos. Autores tais como Agamben e Esposito, para citar dois dos mais proeminentes, procuram explorar o que seria uma certa ambiguidade na maneira pela qual Foucault procurara discernir a natureza da passagem do poder soberano para o biopoder e suas formas possíveis de imbricação e coextensividade na atualidade das democracias liberais. Assim, por exemplo, a julgar-se por uma obra como A vontade de saber, a passagem do poder clássico soberano ao biopoder deve ser compreendida em termos de uma ruptura a partir da qual um poder de gládio, cuja forma de manifestação é a da violência explícita da morte - o causar a morte sob a forma de um poder de confisco - é substituído por um poder que designa uma biopolítica das populações, ou seja, como vimos, um poder que se exerce positivamente sobre a vida: "Pode-se dizer que o velho direito de causar a morte ou deixar viver foi substituído por um poder de causar a vida ou devolver à morte" (FOUCAULT, 1976, p. 181).

Ao contrário, a se considerar os cursos ministrados por Foucault na segunda metade da década de 1970, em especial o curso ministrado no mesmo ano de publicação de $A$ vontade de saber, 1976, intitulado Em 
defesa da sociedade, a passagem da soberania ao biopoder aparece não tanto em termos de uma ruptura mas antes de uma complementaridade ou de uma articulação concertada entre ambos: assim, por exemplo, na aula dedicada ao biopoder, apreende-se que a mais maciça e importante transformação ocorrida no direito público, no século XIX, constituiu não exatamente uma substituição da soberania clássica - do velho direito de "fazer morrer ou deixar viver" —, mas uma modificação que "vai penetrá-lo, perpassá-lo" por meio de "um direito, ou melhor, um poder exatamente inverso: poder de 'fazer' viver e de 'deixar' morrer" (FOUCAULT, 2000,, p. 287); e mais adiante, nesta mesma aula, a questão se coloca em termos de uma emergência da disciplina e do biopoder - ou poder regulamentador - como forma de "acomodação" para sanar a inoperalidade da soberania para reger o "corpo econômico e político de uma sociedade em vias, a um só tempo, de explosão demográfica e de industrialização" (Idem, p. 297-298).

Ora, é a partir desta ambiguidade (a relação entre soberania e bipoder parece se estabelecer em termos de ruptura, ora em termos de continuidade) que Agamben e Esposito, mutatis mutandis, exploram o que teria sido uma insuficiência de Foucault em pensar o nexo entre a biopolítica e a violência soberana estatal, — fenômeno que teria sido elevado à sua enésima potência nos totalitarismos mas que, com efeito, estaria presente nas democracias liberais contemporâneas, seja sob a forma de um Estado de exceção feito à regra soberana do governo, tornado elemento paradigmático da soberania contemporânea liberal - expediente que implica em mobilizar a conhecida tese político-teológica de Carl Schmitt: soberano é aquele que tem o poder de decidir sobre o estado de exceção (AGAMBEN, 2004) —, seja sob a forma do caráter paradoxal da união de uma communitas (ou comunidade) precisamente a partir da immunitas (ou imunidade) enquanto negação de um mútuo pertencimento, elemento que marcaria o desenvolvimento da política moderna com a emergência de uma associação humana não comunitária - o que implica, por sua vez, em revisitar o contratualismo moderno como paradigma da emergência de uma sociedade de indivíduos isolados (ESPOSITO, 2010, p. 255; ESPOSITO, 2003, p. 39-40). No primeiro caso, evidentemente, temos a tese agambeniana 
de uma dúplice estrutura da ordem jurídico-política do Ocidente, que parece responder, a um só tempo, tanto a um elemento normativo e jurídico em sentido restrito quanto a um elemento anômico e extrajurídico (AGAMBEN, 2005, p. 08), de sorte que "Soberana é a esfera na qual se pode matar sem cometer homicídio e sem celebrar sacrifício" (AGAMBEN, 2007b, p. 91) ${ }^{5}$. No segundo, está em jogo a tese espositiana de uma imunização política como "protecção negativa da vida", quer dizer, uma compreensão da prática política moderna capaz de reunir as modalidades de conservação e negação da vida - de sua proteção e destruição maciças - por meio de uma relação de imanência de uma a outra (ESPOSITO, 2010, p. 74-75), o que significa que, "para relacionar-se com a vida, a política pareceria ter que privá-la de toda dimensão qualitativa, tornando-a 'só vida', 'pura vida', 'vida desnuda'” (ESPOSITO, 2009, p. 25), ou seja: o dado biológico é imediatamente biopolítico.

Some-se aqui, igualmente, o manejo da relação entre biopoder e imperium em Mbembe, para o qual a noção mesma de biopoder, sendo insuficiente para dar conta das "formas contemporâneas de submissão da vida ao poder" (MBEMBE, 2018, p. 71), deveria ser complementada pela noção de necropolítica, compreendida como distribuição massiva e industrial (técnica) da morte para tornar possíveis as funções assassinas do Estado (justamente: suas funções de soberania), e isso por meio da constante re-inscrição do racismo no espaço de governamento biopolítico moderno, - a começar pelo sistema colonial de plantation e a exploração da escravidão moderna que lhe é coetânea, a ser considerada como uma das "primeiras manifestações da experimentação biopolítica” (Idem, p. 27). Assim, em Mbembe, a forma de soberania necropolítica que nos é contemporânea - assentada nas bases de uma biopolítica que revela a expressão da soberania como capacidade de

5 Eis o sentido exemplar do homo sacer, figura ambígua do direito romano arcaico, para o pensamento de Agamben: trata-se do termo que designava aquele que foi julgado e condenado por um delito e que, por conta de sua condenação, encontrava-se em uma situação de dupla exceção em relação as leis humanas e divinas, podendo ser morto sem que tal ação se configurasse como homicídio e, no entanto, não podendo ser oferecido em sacrifício. Assim sendo, "soberano é aquele em relação ao qual todos os homens são potencialmente homines sacri e homo sacer é aquele em relação ao qual todos os homens agem como soberanos" (AGAMBEN, 2007b, p. 92). 
matar a fim de viver - paga tributo ao experimento da formação não-comunitária (porque desprovida do "exercício do poder de fala e de pensamento") da estrutura político-jurídica da plantation (Idem). E é nestes termos que Mbembe se valerá da noção de necropolítica - em seu entrecruzamento com o poder gestionário biopolítico e a herança de construção do "negro" como "sujeito racializado" no Ocidente para destacar a moderna distribuição soberana e calculada da morte em contextos em que o estado de exceção se torna a norma por meio da instrumentalização generalizada e da destruição material dos corpos e populações humanas subjugados como descartáveis ou supérfluos (MBEMBE, 2012, p. 135)'

Neste sentido, e sem pretensão de esgotar os usos e os modos de exploração fecundos da relação ambígua entre a soberania e a governamentalidade biopolítica (ou liberal) a partir das sendas deixadas em aberto por Foucault - cuja riqueza tem enformado discussões relevantes sobre a natureza do processo político de nosso presente -, gostaria apenas de indicar o que me parecem alguns dos elementos axiais das diversas interlocuções que a genealogia foucaultiana do governamento têm permitido na atualidade, e que poderiam ser sistematizados a partir de dois aspectos centrais. O primeiro destes aspectos é de ordem propriamente metodológica: a démarche metódica da genealogia foucaultiana implica já em "libertar-se do privilégio teórico da soberania" - ou seja, das análises do poder em termos jurídico-institucionais (FOUCAULT, 1976, p. 116-117) — em favor de uma descrição atenta dos dispositivos concretos a partir dos quais o poder incide sobre os corpos e os gestos dos governados; e é esta "libertação" que permite a Foucault, por exemplo, no caso do liberalismo, apreendê-lo em uma perspectivas que não é aquela de seus aspectos morais e/

6 Assim, dirá Mbembe em sua Crítica da razão negra, "os novos dispositivos de segurança [dispositivos biopolítcos] integram elementos de regimes anteriores (regime disciplinar e de penalização na escravatura, elementos das guerras coloniais de conquista e de ocupação, técnicas juridico-legais de excepção), aplicando-0s, de modo nanocelular, às tácticas características da era do genoma e da 'guerra contra 0 terror'. [...] Aliás, a crescente força do Estado securitário nas actuais circunstâncias vem a par de uma reconfiguração do mundo pelas tecnologias e de uma exacerbação das formas de consignação racial. Face à transformação da economia da violência no mundo, os regimes democráticos liberais consideram-se agora em estado de guerra quase permanente contra novos inimigos fugidios, móveis e reticulares" (MBEMBE, 2014, p. 48). 
ou filosóficos, mas sim, como vimos acima, a de uma prática regular de governo ${ }^{7}$. O segundo aspecto concerne ao próprio diagnóstico de época efetuado pela genealogia foucaultiana: seria importante considerar a ambiguidade da passagem da soberania para a biopolítica em termos de uma tensão que pertenceria, a bem dizer, às próprias tarefas da governamentalidade moderna, tal como Foucault as compreendera em seu diagnóstico de nosso presente ${ }^{8}$, - o que significa, grosso modo, que em suas reflexões sobre o poder moderno Foucault percorre as encarnações e rearranjos políticos da série soberania-disciplina-biopoder (ou segurança), esta que se reinscreve sem cessar no horizonte de nossa prática política moderna na medida em que é continuamente mobilizada no político pelo governamento liberal, egresso do século XVIII. E a esse respeito, talvez se devesse considerar com mais devagar a afirmação foucaultiana segundo a qual o desenvolvimento das artes de governo propriamente gestionários da população retomou, com uma acuidade inaudita, o problema da soberania, uma vez que não se tratava mais, como nos séculos XVI ou XVII, de deduzir das teorias da soberania uma arte de governo, mas sim de partir de uma arte de governo já existente para "ver que forma jurídica, que forma institucional, que fundamento de direito seria possível conferir à soberania que caracteriza um Estado" (FOUCAULT, 2004a, p. 109-110).

Com relação ao primeiro ponto, e como elemento complementar à recusa metodológica da genealogia em assumir a perspectiva das teorias da soberania, há que se compreender que constitui o traço da metodologia foucaultiana, em geral, o procedimento de trabalhar com tipologias paradigmáticas das formações históricas e/ou dos objetos que constituem suas temáticas, e que são dispostas ao modo da ruptura. ${ }^{9}$

7 Daí 0 esforço de Agamben em explorar dois campos deixados em aberto pelas pesquisas genealógicas de Foucault: 0 direito e a teologia (AGAMBEN, 2005, p. 2).

8 Esposito nota a "tensão" entre soberania e biopolítica no "discurso" de Foucault, mas prefere tomá-la em termos de uma antinomia interna ao seu pensamento, em lugar de considerá-la em termos de uma articulação concertada , apresentando a questão nos seguintes termos: "Ou a biopolítica produz subjectividade ou produz morte"; "numa extremidade a produção de uma nova subjetividade [biopolítica] e na outra sua destruição radical [o potencial de causar a morte próprio à soberania e, in extremis, a uma tanapolítica]" (2010, p. 55-56).

9 Ao menos desde o seu 0 reino e a glória (2007), e mais marcadamente em Signatura Rerun: sobre o método (2008), Agamben tem explorado, de modo peculiar, a noção de "paradigma" em Foucault, propondo um conceito de paradigma compreendido 
No caso que nos interessa, estamos diante de tipologias de governamento estatal que, escandidas em ruptura, se apresentam do modo como se segue: o Estado de Justiça, nascido em uma territorialidade de tipo feudal; o Estado Administrativo dos séculos XV e XVI, correspondente a uma sociedade de regramentos e disciplinas com uma territorialidade de fronteiras não feudal; e o Estado Governamental propriamente dito, uma arte de governo que, egressa do século XVIII, possui por objeto principal a população, por forma majoritária de saber a economia política e por instrumento técnico central os dispositivos de seguridade (sendo o território, neste caso, "apenas" uma variável) (FOUCAULT, 2004a, p. 111). Portanto, seria possível considerar que a ruptura por vezes manifesta entre soberania e biopolítica se impõe pelo mesmo motivo que a abordagem epistêmica de As palavras e as coisas, por exemplo, também é da ordem da ruptura: ela é derivada do corte metodológico foucaultiano, que responde, por seu turno, às necessidades de uma filosofia da diferença ${ }^{10}$. Assim sendo, como assinala Judith Revel a propósito do método em Foucault, a "ruptura é, em si mesma, um elemento significante porque marca a história com sua quebra interna, assim como eleva à dignidade do sentido o não-linear, o desordenado, o despropósito" (REVEL, 2004, p. 70). Donde, se quisermos, os momentos em que no nível do método, soberania e biopolítica - formas paradigmáticas, e não exatamente realidades historicamente verificáveis - se apresentam em relação de ruptura: o tema da descontinuidade, ou da ruptura, colhe seus frutos na medida em que a diferença - por

como um "exemplo", ou "modelo", cuja função não é a de tratar de "fenômenos históricos positivos", mas sim a de "constituir e fazer inteligível um inteiro e mais amplo contexto histórico-problemático" (AGAMBEN, 2008, p. 11).

10 É verdade que entre As palavras e as coisas, obra pertencente à fase arqueológica do pensamento foucaultiano, e a genealogia da década de 1970 Foucault produz não poucos deslocamentos em suas investigações. Mas tais deslocamentos constituem antes, nas palavras do próprio Foucault de $A$ ordem do saber, uma "diferença [que] não é tanto de objeto ou de domínio, mas sim de ponto de ataque, de perspectiva" (FOUCAULT, 1996, p. 66-67). Assim, entre a arqueologia dos anos 1960 (dedicada ao modo de inserção discursiva dos diversos sujeitos na condição de objetos para um saber ordenador) e a genealogia nascente nos anos 1970 (atenta à maneira como estes mesmos sujeitos, informados pelo saber ordenador, tornam-se o lugar de exercício de um poder caracterizado por divisões normativas), um mesmo nexo fundamental permanece: não há poder sem regime de verdade e não há verdade sem regime de poder. Ou ainda: "0 discurso não é simplesmente aquilo que traduz as lutas ou os sistemas de dominação, mas aquilo por que, pelo que se luta, o poder de que queremos nos apoderar' (Idem, p. 10). Nesta medida, o método, em Foucault, continua a responder às exigências de uma filosofia da diferença: trata-se, nas palavras do Deleuze de Diferença e repetição, de "Resgatar a diferença de seu estado de maldição", isto é, de sua subordinação à identidade (DELEUZE, 2003, p. 44). 
anteposição inclusiva - constitui a identidade, eminentemente normativa, de nossos regimes de saber-poder. Ademais, é operando por ruptura e recusa às teorias da soberania que Foucault se encontra em condições de circunscrever a distinção entre "normalização" (procedimento característico do poder disciplinar e do biopoder) e o sistema jurídico dos procedimentos legais que lhe correspondem.

Com relação ao segundo ponto levantado acima, relativo ao diagnóstico de época efetuado pela genealogia foucaultiana, e que poderia nos levar a considerar a ambiguidade da natureza da passagem da soberania a biopolítica como sendo constitutiva de uma tensão pertencente às tarefas políticas da governamentalidade contemporânea, constitui um importante elemento a questão que Foucault pretende encaminhar aos seus ouvintes na aula do dia 17 de março de Em defesa da sociedade, e que será retomada em $A$ vontade de saber: se é possível admitir a hipótese da emergência histórica, na modernidade, de uma forma de exercício de poder que concerne à gestão e majoração da vida das populações, para fins de sua captura positiva no interior dos cálculos do poder político estatal, como compreender, ao mesmo tempo, o fato histórico de uma produção crescentemente industrial da morte ao longo dos séculos XIX e XX (sobretudo tendo-se em vista os fenômenos totalitários)? (FOUCAULT, 2000, p. 303-304; FOUCAULT, 1976, p. 179). Neste ponto, estamos no nódulo da tensão entre soberania e biopolítica em Foucault; e a resposta a esta espécie de copertencimento do direito soberano de matar e do governamento gestionário da vida na modernidade encontrará no racismo seu campo de articulação , ou, mais precisamente, em um racismo constitutivo dos estados liberais modernos (temática que ganhará altura considerável particularmente nas considerações de Mbembe sobre a necropolítica $)^{11}$.

11 "Na formulação de Foucault, o biopoder parece funcionar mediante a divisão entre as pessoas que devem viver e as que devem morrer. Operando com base em uma divisão entre os vivos e os mortos, tal poder se define em relação a um campo biológico do qual toma o controle e no qual se inscreve. Esse controle pressupõe a distribuição da espécie humana em grupos, a subdivisão da população em subgrupos e 0 estabelecimento de uma cesura biológica entre uns e outros. Isso é que Foucault rotula com 0 termo (aparentemente familiar) de 'racismo"' (MBEMBE, 2018, p. 18). E ainda, referindo-se às colônias: "as colônias são zonas em que guerra e desordem, figuras internas e externas da política, ficam lado a lado ou se alternam. Como tal, as colônias são 0 local por excelência em que os controles e as garantias de ordem judicial podem ser suspensos - a zona em que a violência do estado de exceção supostamente opera a serviço da "civilização" (MBEME, 2018, p. 35). 
Assim sendo, em Foucault o arcani imperi constitutivo de nossa modernidade politica - que Agamben pretende fazer recuar consideravelmente (2007b, p. 16) - se assenta na importância vital (em sentido amplo) do racismo para a forma moderna de funcionamento do poder biopolítico, uma vez que ela não denega a função assassínia da soberania (daí a ambiguidade da relação entre vida e morte em regime de biopoder), mas a submete a fins diversos que são da ordem do estabelecimento de uma cesura imanente constitutiva de um imperativo de morte para a segurança mesma do corpo político, compreendido em sua dimensão populacional e, portanto, no sentido da formação de camadas de populações de indesejáveis cuja morte direta ou a exposição à morte garante a promessa de segurança a todos:

Vocês compreendem, em consequência, a importância - eu ia dizer a importância vital - do racismo no exercício de um poder assim: é a condição para que se possa exercer o direito de matar. Se o poder de normalização [biopoder] quer exercer o velho direito soberano de matar, ele tem de passar pelo racismo. E se, inversamente, um poder de soberania, ou seja, um poder que tem direito de vida e de morte, quer funcionar com os instrumentos, com os mecanismos, com a tecnologia de normalização [biopoder], ele também tem de passar pelo racismo. É claro, por tirar a vida não entendo simplesmente o assassinato direto, mas também tudo o que pode ser assassínio indireto: o fato de expor à morte, de multiplicar para alguns o risco de morte ou, pura e simplesmente, a morte política, a expulsão, a rejeição, etc. (Idem, p. 306).

É certo que Foucault avançará em suas pesquisas, nos anos precedentes, abandonando a temática do racismo em favor de uma descrição positiva dos mecanismos de governamento da biopolítica, fazendo cruzar as noções de biopoder, governamento e racionalidade governamental liberal e/ou neoliberal. E nesse sentido Esposito parece ter razão ao considerar que as filosofias contratualistas teriam sido o "terreno natural" de encontro entre a arcaica ordem soberana e o novo aparato governamental biopolítico, advertindo-nos, no entanto, que essa relação, plausível no plano histórico, não esgota a questão no plano teórico (ESPOSITO, 2010, p. 66). Mas, para além da importância do modelo contratualista como ponto de contato entre a 
soberania e a biopolítica, a noção mesma de biopoder e a descrição positiva dos dispositivos securitários liberais permitirá a Foucault divisar uma lógica de funcionamento do poder que, correspondendo a um conjunto de procedimentos gestionários da vida, compreende a violência soberana latente na modernidade liberal como uma expressão das múltiplas variações internas de uma mecânica de captura dos corpos que distribuí, socialmente, a morte para tornar possíveis as estruturas gestionárias securitárias do Estado biopolítico. Neste sentido, a ambiguidade das relações entre o poder soberano e o biopoder nos Estados securitários contemporâneos revela sua natureza efetiva não sob a forma de uma alternativa estrita entre ambos, mas sim por meio de uma tarefa de governamento que implica em reinscrever incessantemente o racismo no político para manejar uma interseccionalidade ${ }^{12}$ que indica não uma subordinação do poder soberano ao biopoder, mas um entrelaçamento progressivo, e sempre a refazer-se, entre o exercício de sobernia política do direito de morte e as estruturas modernas da biopolítica, ou seja, da política securitária das populações

$\mathrm{Na}$ esteira das considerações de Mbembe sobre o tema em seu ensaio Necropolítica - " "a gestão, a proteção e o cultivo da vida [são] coextensivos ao direito soberano de matar" (2008, p. 19) —, interessa-nos sublinhar, à guisa de conclusão, o espaço de mútuo pertencimento entre o biopoder, o liberalismo (compreendido como lógica biopolítica de governamento) e a produção, de tipo soberana, de largas franjas populacionais de indesejáveis destinados à exposição sistemática de suas vidas ao extermínio. Assim, se a biopolítica se caracteriza pela gestão da vida biológica em seus processos de regulação populacional, resta que a morte, ou a "necropolítica", lhe é absolutamente coextensiva na medida em que o poder soberano é constitutivo de seus processos, e

12 A noção de "interseccionalidade", que remonta ao movimento Black Feminism do final dos anos 1970, ganha seu uso conceitual mais sistemático e corrente a partir de um texto da jurista afro-americana Kimberlé W. Crenshaw, intitulado "Demarginalizing the intersection of race and sex" (CRENSHAW, 1989), passando a designar, progressivamente, a interdependência das relações de poder de raça, sexo e classe. Nos interessa, no contexto deste artigo, o uso da noção de interseccionalidade para, justamente, não apenas reconhecer a multiplicidade operatória dos sistemas e dispositivos de poder mas, igualmente, sua interação na produção e reprodução dos sistemas de governo e dominação políticas (cf. BILGE, 2009, p. 70). 
isso não apenas com relação as guerras ou ao inimigo externo, mas também como forma regulamentar de produção interna da função assassina do Estado moderno.

\section{Referências}

ADORNO, F. P. Editorial. Klésis, Revue Philosophipe: La Biopolitique, n. 08, p. $2-4,2008$.

AGAMBEN, G. Estado de exceção. Trad. Iraci D. Poleti. São Paulo: Boitempo, 2004.

AGAMBEN, G. Da teologia política à teologia econômica: entrevista com Giorgio Agamben. Revista internacional interdisciplinar Interhesis, v. 2, n. 2, jul./ dez. 2005. Disponível em: <https://periodicos.ufsc.br/index.php/interthesis/article/view/734/10790>. Acesso em: 10 jan. 2019.

AGAMBEN, G. Il regno e la gloria: per una genealogia teologica dell'economia e del governo. Vicenza: Neri Pozza, 2007a.

AGAMBEN, G. Homo sacer. O poder soberano e a vida nua I. Trad. Henrique Burigo. São Paulo: Boitempo, 2007b.

AGAMBEN, G. Signatura rerum. Sul metodo. Torino: Bollati Boringhieri, 2008. BIDET, J. Foucault avec Marx. Paris: La Fábrique Éditions, 2014.

BILGE, S. Théorisations féministes de l'intersectionnalité. Diogène, n. 225, p. 70-88, 2009. Disponível em: <https:// www.cairn.info/revue-diogene-2009-1-page-70.html>. Acesso em: 15 jan. 2019.

BLANCHETTE, L-P. Michel Foucault: Genèse du biopouvoir et dispositifs de sécurité. Lex Electronica, v. 11, n. 2, p. 1-11, 2006. Disponível em: <https:/ / www.lex-electronica.org/files/sites/103/11-2_blanchette.pdf>. Acesso em: 12 jan. 2019. 
CRENSHAW, K. W. Demarginalizing the intersection of race and sex; a black feminist critique of discrimination doctrine, feminist theory and antiracist politics. University of Chicago Legal Forum, Iss. 1, article 8, p. 139-167, 1989. Disponível em: <https://chicagounbound.uchicago.edu/cgi/viewcontent. cgi? article=1052\&context=ucl $>$. Acesso em: 12 jan. 2019.

DELEUZE, G. Différence et Répétition. Paris: PUF, 2003.

ESPOSITO, R. Biopolitica e filosofia. Trad. M. Freitas da Costa. Lisboa: Edições 70, 2010.

ESPOSITO. R. Communitas: origen y destino de la comunidad. Trad. Carlo Rodolfo Molinari Marotto. Buenos Aires: Amorrortu Editores, 2003.

ESPOSITO, R. Immunitas. Protección y negación de la vida. Trad. Carlo Rodolfo Molinari Marotto. Buenos Aires: Amorrortu, 2009.

FOUCAULT, M. La volonté de savoir. In: Histoire de la Sexualité, v. 1. Bibliothèque des Histoires. Paris: Gallimard, 1976.

FOUCAULT, M. Em defesa da sociedade: curso no Collège de France (1975-1976). Trad. Maria Ermantina Galvão. São Paulo: Martins Fontes, 2000.

FOUCAULT, M. Le sujet et le pouvoir. In: Dits et écrits II. 1976-1988. Paris: Quarto Gallimard, 2001.

FOUCAULT, M. O nascimento da medicina social. In: MACHADO, R. (org.). Microfísica do poder. Trad. Roberto Machado. Rio de Janeiro: Edições Graal, 2002, p. 79-98.

FOUCAULT, M. Sécurité, territoire, population: cours au Collège de France (1977-1978). Collection “Hautes Études”. Paris: Gallimard/Seuil, 2004a.

FOUCAULT, M. Naissance de la biopolitique: cours au Collège de France (19781979). Collection “Hautes Études”. Paris: Gallimard/Seuil, 2004b.

MBEMBE, A. Necropolítica. Trad. Renata Santini. São Paulo: n-1 Edições, 2018.

MBEMBE, A. Necropolítica: una revisión crítica. In: MC GREGOR, H. C. Estética y violência: necropolitica, militarizacion y vidas lloradas. México: Universidade do México. 2012, p. 130-140. 
MBEMBE, A. Crítica da razão negra. Trad. Marta Lança. Lisboa: Antígona, 2014. REVEL, J. O pensamento vertical: uma ética da problematização. In: GROS, F. (org.). Foucault: a coragem da verdade. Trad. Marcos Marcolino. São Paulo: Parábola Editorial, 2004. p. 65-87.

Recebido: 19/01/2019:

Received: 01/19/2019

Aprovado: 26/03/2019

Approved: 03/26/019 